Uncertainty about how an individual can prepare for and respond to an event and what steps the government is taking to protect them can leave the public confused and anxious. However, with education, the public can learn what is true and what is erroneous about bioterrorism.

The authors will address many of the "common knowledge" aspects of bioterrorism and attempt to dispel many of the "facts" so widely accepted throughout society by both professionals and laymen alike. Coupled with this will be a discussion of some of the key aspects of crisis communication and preparation that can help reduce or eliminate much of the confusion attendant to a bio-terror incident. The following eight "myths" will be discussed: (1) we can accurately predict and detect bioterrorist attacks; (2) bioterrorism will be preceded by a warning; (3) bioterrorism preparedness essentially is identical to planning for chemical, radiological, or nuclear attacks; (4) we will be able to rapidly determine whether an epidemic is natural or the result of bioterrorism; (5) nothing can be done to prepare the civilian population for a bioterrorist attack; (6) effective preparedness for a bioterrorism attack can be achieved without major investments in basic bio-scientific research; (7) hospitals can treat a large influx of patients following a bioterrorist attack; and (8) bioterrorism preparedness and response is a national responsibility.

Keywords: auto-immune deficiency syndrome (AIDS); bioterrorism; misinformation; misperception; preparedness; severe acute respiratory syndrome (SARS)

Prebosp Disast Med 2005;20(2)::60-s61

\section{Lessons Learned from Terrorism-Related Injuries in Israeli Civilians}

K. Peleg; L. Aharonson-Daniel

Israel National Center for Trauma and Emergency Medicine

Research, Israel

Introduction: Terror-related injuries have become a threat for people all over the world. In Israel, from October 2000 to December 2003, 6,049 people were injured, and 904 were killed by terrorist attacks. Many lessons have been learned from the necessity to deal with such a large number of frequent mass-casualty events. This presentation aims to share the Israeli experience with other nations that may face the risk of terrorism.

Methods: An analysis of national trauma registry data from October 2000-December 2003 was performed.

Results: Lessons learned will be described and practical information on enhancing preparedness for treating casualties from acts of terrorism will be provided. Lessons include: (1) arrival and hospitalization patterns-do the most severe injuries arrive first?; (2) triage-has triage changed due to new mechanisms of penetrating injuries such as shrapnel nails and bolts included in explosives?; and (3) differences in resource consumption by terrorism-related casualties.

Conclusion: The audience should better appreciate the various aspects of handling of mass-casualty events, identify factors that contribute to the severity and outcome of terrorism-related injuries, know what can be expected under specific attack types, and learn some of the most important implications for preparedness for such situations.
Keywords: characteristics; injuries; Israel; management; mass-casualty events; preparedness; terrorism

Prebosp Disast Med 2005:20(2):s61

\section{Keynote 3: CBRN/HAZMAT}

Chair: Per Kulling

Director, Department of Emergency and Disaster Planning, National Board of Health and Welfare, Sweden

\section{Keynote 4: Children and Terrorism: The Dagestan, Nord-Ost, and Beslan Experiences \\ Chair: Leonid Roshal}

Children's Clinical and Research Institute of Emergency Surgery and Trauma, Moscow

\section{Friday 20th May 2005}

\section{Non-Governmental Organizations and the WADEM}

Chair: Knut Ole Sundnes

\section{Plenary 3: The Politics of Disaster Relief}

\author{
Medical Capacity of Disaster First Responders in \\ Turkey \\ G. Ozel; S. Yaylaci; E. Noji \\ Nationally Registered Emergency Medical Technician-Paramedic \\ (NREMT-P), USA
}

Objective: The aim of the present review was to assess the current medical capability of disaster first-response units such as Civil Defense Units and National Medical Response teams in Turkey and to make recommendations for a model of structure and training of such teams.

Needs Assessment: The Marmara Earthquake in 1999 and several other major disasters since then made it clear that Turkey lacks the availability of well-trained, medical, firstresponder teams to perform medical care while working closely with search and rescue (SAR) units during the initial response to disasters.

Current Situation: Turkish Civil Defense Units are the primary sources to respond to disasters and perform SAR operations. While these units' main focus is SAR, they lack the capacity to provide medical care beyond basic life support to other unit members and disaster victims. The Ministry of Health recently has approved a model program to form and train medical response units to operate during disasters. The National Medical Response Teams (UMKE in Turkish) are based on volunteer membership from doctors and other allied health practitioners. However, there seems to be no screening process for appropriateness of team members to specified tasks. The 40 -hour curriculum currently taught to UMKE members covers only principles of disaster medical response and is not inclusive enough to address disasters other than earthquakes. This curriculum does not address such critical topics as hazardous materi$\mathrm{als} /$ weapons of mass destructions concepts, decontamination 